\title{
Numerical Simulation on Mechanical Response of Buried Pipeline under Uneven Settlement
}

\author{
Yanhua Chen ${ }^{1,2, *}$, Qikun $\mathrm{Ma}^{3}$, Dongdong $\mathrm{Li}^{1}$, Mei Yang ${ }^{1,2}$ and Luzhen Jiang ${ }^{4}$ \\ ${ }^{1}$ School of Civil Engineering, North China University of Science and Technology, Tangshan 063009, China \\ ${ }^{2}$ Earthquake Engineering Research Center of Hebei Province, Tangshan 063009, China \\ ${ }^{3}$ Tangshan Polytechnic College, Tangshan 063020, China \\ ${ }^{4}$ Hebei University of Science and Technology, Shijiazhuang 050018, China \\ ${ }^{*}$ Corresponding author
}

\begin{abstract}
Uneven settlement will cause the buried pipeline deformed, even crack. A 3-D finite element model for buried pipeline was established by ADINA to investigate the deformation of pipe under uneven settlement. Furthermore, the effects of some key factors on mechanical response of buried pipeline were analyzed. Results indicate that the maximum axial stress increases with the decreases of diameter and wall thickness, the increases of the soil stiffness and buried depth.
\end{abstract}

Keywords-buried pipeline; mechanical response; uneven settlement; numerical simulation; ADINA

\section{INTRODUCTION}

Earthquake, exploitation and utilization of underground space often cause uneven settlement of site, which does harm to the normal use of underground and ground infrastructure. Buried pipeline is subjected to large loading, and is deformed greatly, even to crack under the uneven settlement of soil. Pipe crack will result in fluid leakage, polluting environment seriously, doing harm to people's health. So, researchers have carried a lot of works on damage of buried pipeline under site deformation. B.A.Wols and his partners developed several methods for predicting pipe stresses or pipe failure resulting from uneven settlement, such as empirical method, finite element method and GIS method [1-3]. Luo et al simulated the mechanical behavior of polyethylene pipe under foundation settlement by ABAQUS [4]. Yang and Bai used ANSYS to simulate the deformation of buried pipeline under earthquake settlement [5]. Analytical methods for analyzing the mechanical response of buried pipeline under site settlement have been carried, and some simple equations have been derived [6-8].

It can be seen that some factors are important to the mechanical response of buried pipeline under uneven settlement. And the numerical method is necessary for analyzing the effects of these factors. So, a finite element model is established by ADINA in this paper, which is used to investigate the stress and deformation of buried pipeline under uneven settlement. It can provide some advices for engineering design and protection.

\section{Buried Pipeline Under UneVEn Settlement}

Complex forces act on the buried pipeline for uneven settlement, which includes soil pressure on the upper and sides of pipe, support force of bottom soil, gravity of pipe, gravity and pressure of internal fluid, and friction between pipe and soil. Under uneven settlement, the whole region can be divided into settlement region and non settlement region as Figure 1.

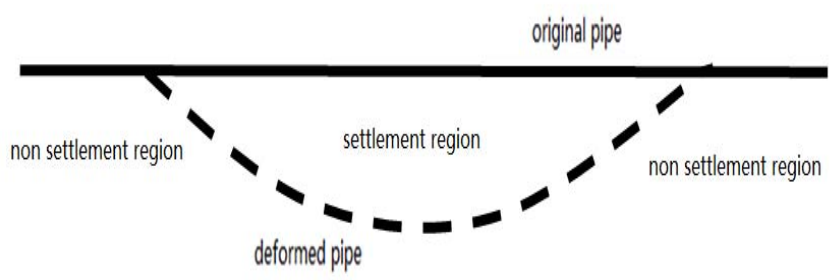

FIGURE I. SCHEMATIC DIAGRAM OF BURIED PIPELINE UNDER UNEVEN SETTLEMENT

\section{Finite Element MODEL}

\section{A. Basic Assumptions}

1) Continuous pipeline is considered, joints and other pipe fitting are not included.

2) The wall thickness of pipeline is very thin.

3) Comparing with the diameter of pipe, the size of soil is large enough.

4) Friction of pipe-soil is considered.

5) Pipe and soil are isotropic materials.

\section{B. Geometric Model}

Considered the symmetry of the Figure 1, a half of Figure 1 is selected. So, by parasolid and native method in ADINA, geometrical model is established as Figure 2. Some geometry and other parameters of the model are shown in Table 1 . The length of pipe is equal to soil length. 


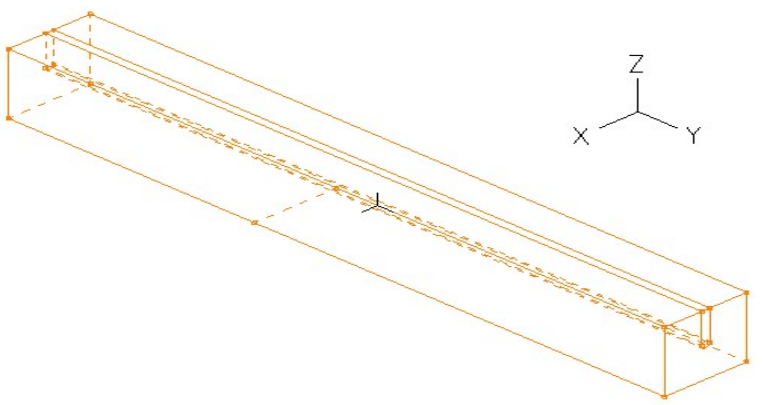

FIGURE II. GEOMETRIC MODEL

TABLE I. GEOMETRY MODEL PARAMETER

\begin{tabular}{|c|c|}
\hline Parameters & values \\
\hline Length of pipe/m & 24 \\
\hline Diameter of pipe/m & 0.3 \\
\hline Thickness of pipe/m & 0.01 \\
\hline Buried depth/m & 1.5 \\
\hline Size of soil/(m $\times \mathrm{m} \times \mathrm{m})$ & $24 \times 3 \times 3$ \\
\hline Length of settlement region $/ \mathrm{m}$ & 15 \\
\hline Length of non settlement region $/ \mathrm{m}$ & 9 \\
\hline
\end{tabular}

C. Definitions of Model

1) Defining materials: Soil and pipe are defined as Table 2 and 3, respectively. The curve of stress and strain of pipe is shown as Figure 3.

TABLE II. DEFINITIONS OF SOIL MATERIAL

\begin{tabular}{ccccccc}
\hline $\begin{array}{c}\text { Soil } \\
\text { material }\end{array}$ & $\begin{array}{c}\text { Type of } \\
\text { material }\end{array}$ & $\begin{array}{c}\text { Density } \\
\boldsymbol{\rho}_{\mathrm{s}} / \mathbf{k g} / \mathbf{m}^{\mathbf{3}}\end{array}$ & $\begin{array}{c}\text { Poisson's } \\
\text { ratio } \boldsymbol{\mu}_{\mathrm{s}}\end{array}$ & $\begin{array}{c}\text { Elastic } \\
\text { modulus } \\
\boldsymbol{E}_{\mathrm{s}} / \mathbf{M P a}\end{array}$ & $\begin{array}{c}\text { Cohesion } \\
\mathbf{F}_{\mathrm{i}} / \mathbf{k P a}\end{array}$ & $\begin{array}{c}\text { Friction } \\
\text { angle } \boldsymbol{\varphi} \mathbf{o}^{\mathbf{0}}\end{array}$ \\
\hline clay & $\begin{array}{c}\text { Mohr- } \\
\text { Coulomb }\end{array}$ & 1880 & 0.37 & 8 & 32 & 18.3 \\
\hline
\end{tabular}

TABLE III. DEFINITIONS OF PIPE MATERIAL

\begin{tabular}{ccccc}
\hline $\begin{array}{c}\text { pipe } \\
\text { material }\end{array}$ & Type of material & $\begin{array}{c}\text { Density } \\
\boldsymbol{\rho}_{\mathrm{p}} / \mathbf{k g} / \mathbf{m}^{3}\end{array}$ & $\begin{array}{c}\text { Poisson's ratio } \\
\boldsymbol{\mu}_{\mathrm{p}}\end{array}$ & $\begin{array}{c}\text { Elastic } \\
\text { modulus } \\
\boldsymbol{E}_{\mathbf{p}} / \mathbf{M P a}\end{array}$ \\
\hline X-60 steel & $\begin{array}{c}\text { Bilinear elastic- } \\
\text { plastic }\end{array}$ & 7800 & 0.3 & $2.1 \times 10^{5}$ \\
\hline
\end{tabular}

2) Constraint condition and loading: In non settlement region, the left ends of soil and pipe are fixed. And the right ends of soil and pipe are fixed at direction $\mathrm{X}$ and $\mathrm{Y}$ in settlement region. It can be seen as Figure 4.

Gravity is applied on the whole model, and is constant. Displacement loading is applied on the bottom of soil in settlement region, which is simulated the uneven settlement of soil. The loading is applied linearly. Loading time is $10 \mathrm{~s}$, and is done by 10 steps. The downward displacement is $0.15 \mathrm{~m}$.

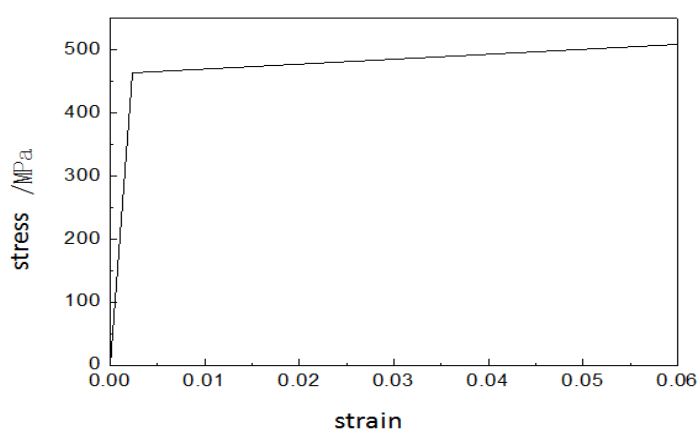

FIGURE III. STRESS-STRAIN CURVE OF X-60 STEEL

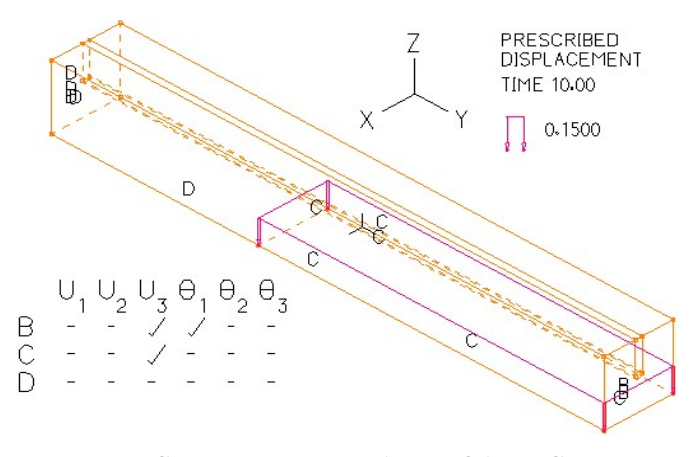

FIGURE IV. FIXITY AND LOADING

3) Defining units and meshing: The pipe is defined as shell unit with 4 nodes. Unit length along pipe axis is $0.2 \mathrm{~m}$. The soil is defined as 3-D solid unit with 4 nodes. Unit length of upper soil is $0.2 \mathrm{~m}$, and unit length of pipe side soil is $0.4 \mathrm{~m}$.

4) Defining friction of pipe-soil: The friction of pipe-soil is 3-D contact, which can be realized by defining contact groups, contact surfaces and contact pairs. In this model, the contact group is 3-D type which includes 2 contact pairs. Also, pipe is defined as target surface, and soil is contact surface. The frictional coefficient is set as 0.5.

According to the above, the finite element model is established as Figure 5. Then, solve and analyze the stresses and deformation of pipeline under uneven settlement.

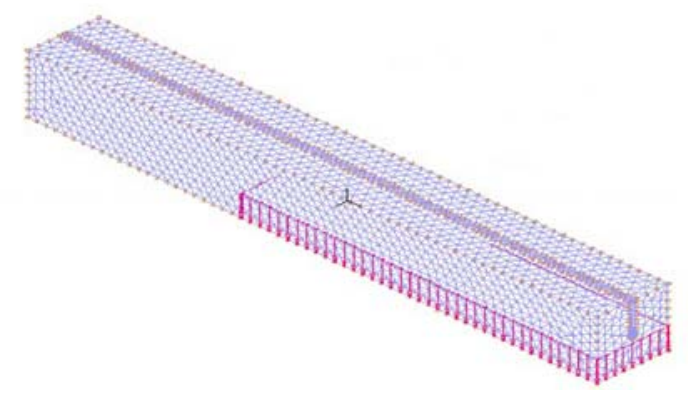

FIGURE V. THE FINITE ELEMENT MODEL

\section{Results AND Discussions}

\section{A. Deformation and Axial Stress of Pipe}

When settlement displacement arrives at $0.15 \mathrm{~m}$, the vertical displacement of pipe along the axial direction is shown as 
Figure 6. It can be seen that local settlement of soil results in the large vertical displacement of pipe with no local support of soil in the settlement region. The deformation of pipe in this region is larger than that in the non settlement region. The vertical displacement of pipe increases suddenly near the interface of two regions, which is at $8 \mathrm{~m}$ in the Figure 6 . The maximum displacement of pipe is at the center of the settlement region, because the support of soil at the position is the least.

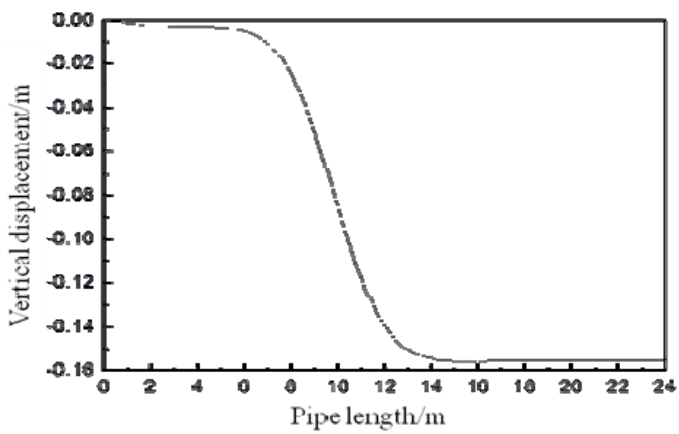

FIGURE VI. VERTICAL DISPLACEMENT OF PIPELINE

The axial stresses of the top, the side and the bottom of pipe are shown as Figure 7. It can be seen that the axial stresses of the top and the bottom of the pipe are symmetrical. The state of tension and compression for the top and the bottom at the same position is opposite. The axial stress of the side of pipe is very small, near zero. In non settlement region, the top of the pipe is subjected to tension and the bottom is subjected to compression. The axial stress is near zero at the center of the settlement region. In the settlement region, the top is subjected to compression and the bottom is tension. Because the soil moves downward, the support loading of soil on the pipe is losing. The pipe near the junction of the two regions is subjected to large load and bends. Also, there are two obvious back bending points near the junction at which the pipe bends seriously. So the pipe near the junction is easy to crack.

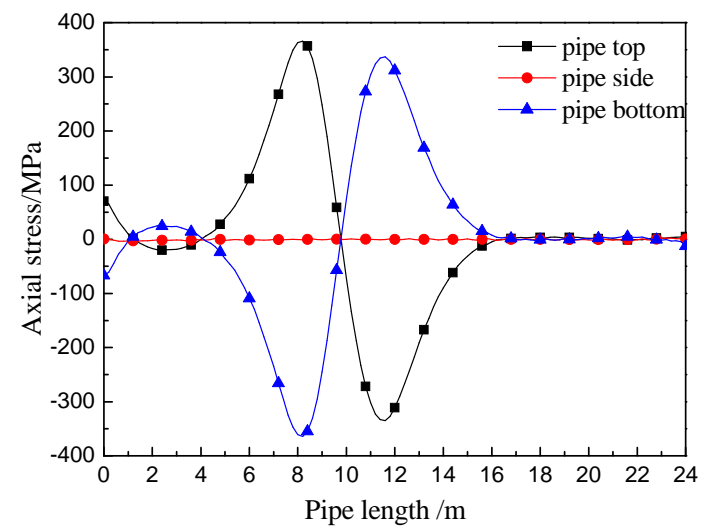

FIGURE VII. AXIAL STRESS ALONG THE PIPELINE

\section{B. Effects of the Diameter and Wall Thickness of Pipe}

When the diameter is $0.1 \mathrm{~m}, 0.3 \mathrm{~m}$, and $0.5 \mathrm{~m}$ respectively, the axial stress of pipe is shown as figure 8 . It can be seen that the axial stress near the junction of the two regions is larger with the decrease of the diameter of pipe. Because diameter is large, the flexural rigidity is larger and the axial stress is less than that of small diameter pipe. Also, the influent range of axial stress of pipe becomes larger. For small diameter pipe, some axial stresses exceed the yield strength, and the points with these values are easy to crack. So, proper diameter should be selected to improve the distribution of the stress of pipe and slow down the abrupt change of stress in the case of satisfying the design and normal operation.

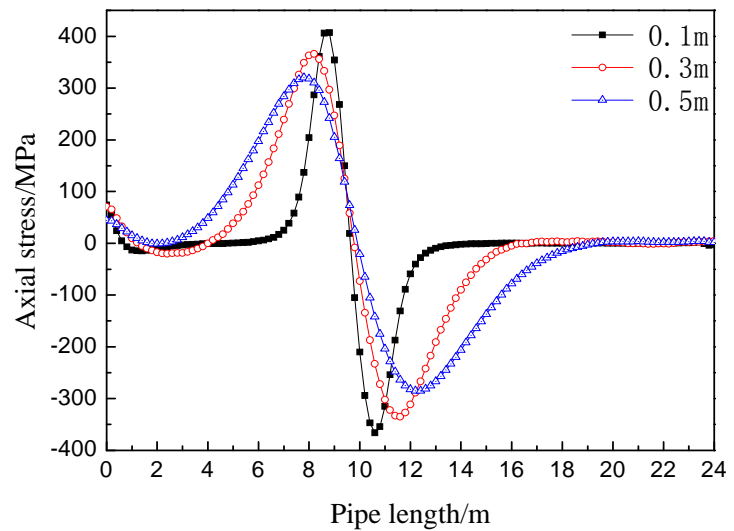

FIGURE VIII. EFFECT OF DIAMETER ON AXIAL STRESS

Figure 9 is the axial stress vs. the pipe length under the different wall thickness of pipe. It can be seen that the axial stress decreases with the increase of the wall thickness and the influent range is identical. When thickness is $6 \mathrm{~mm}$, the stress at the junction of the two regions is very large and yields to crack. When thickness increases to $10 \mathrm{~mm}$, stress distribution is better than $6 \mathrm{~mm}$, and the maximum stress does not reach the yield limit. But the thickness is $12 \mathrm{~mm}$, and the improvement of stress distribution is not obvious. So, wall thickness is no longer a main factor for pipe crack when it reaches a certain range. In actual engineering, a certain thickness is necessary to ensure the safety of the buried pipe.

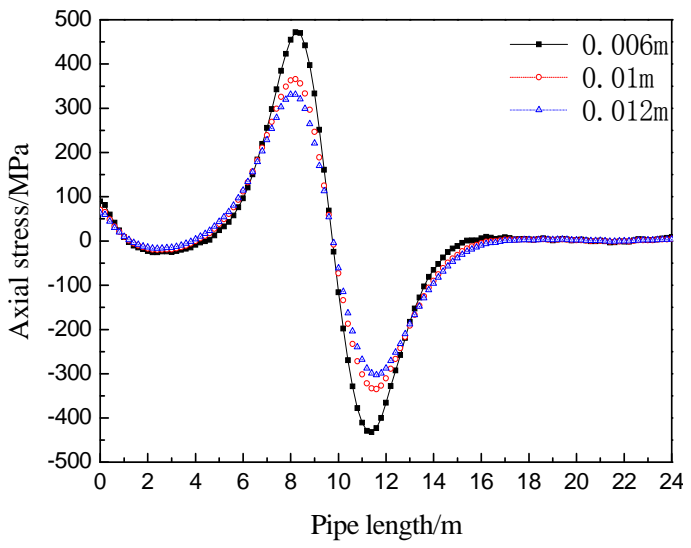

FIGURE IX. EFFECT OF THICKNESS ON AXIAL STRESS

\section{Effect of soil Stiffness}

When the elastic modulus is different, the axial stress of the top of pipe is shown as Figure 10. 


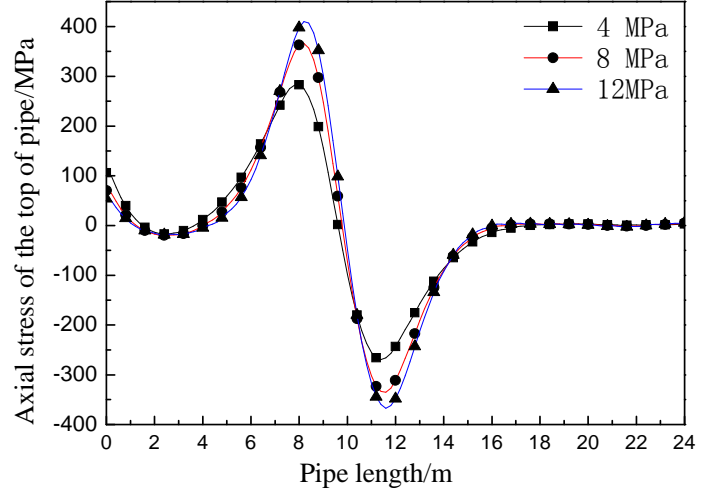

FIGURE X. EFFECT OF SOIL STIFFNESS ON AXIAL STRESS

The stiffness of soil will change the local stress state of pipe. In the transition region (7-14m), the soil stiffness will affect the stress obviously. With the increase of the elastic modulus of soil, stiffness of soil increases and the maximum axial stress of the top of the pipe increases. In the non settlement region (0$7 \mathrm{~m})$ and the center of settlement region (14-24m), there is no relative displacement difference between soil and pipeline, so the effect of soil stiffness on pipe is small and the axial stress changes little with the changing of elastic modulus of soil. In engineering, decreasing soil stiffness is an effective measure.

\section{Effect of Buried Depth}

Figure 11 is the curve of axial stress vs. pipe length with different buried depth. It can be seen that the maximum axial stress of pipe near the junction of the two regions will increase with the increase of the buried depth. It indicates that shallow burying is benefit for protecting pipe. But in engineering, in order to prevent from traffic loading and some accumulations, some polyethylene foam with high strength can be set on the top of the pipe to reduce the pressure on the pipe.

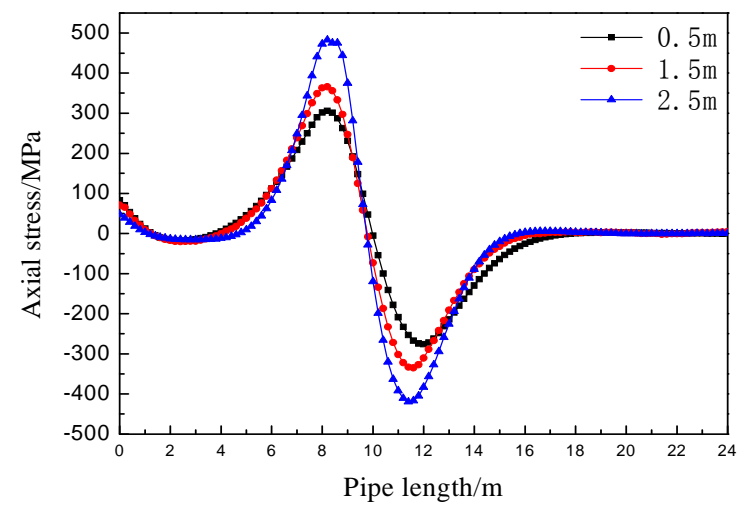

FIGURE XI. EFFECT OF BURIED DEPTH ON AXIAL STRESS

\section{CONCLUSION}

Based on ADINA, 3-D finite element model of buried pipeline is established under uneven settlement. The effects of some factors on the deformation and axial stress of pipe are analyzed. Some conclusions are obtained.
1) Under uneven settlement of soil, the maximum axial stress and the deformation of pipe are located near the junction of the settlement region and non settlement region. The maximum displacement of pipe is at the center of the settlement region. So pipe in the area near the junction of the two regions is very weak.

2) The diameter and wall thickness of pipe are main influence factors for buried pipeline under uneven settlement of soil. The pipe with small ratio of diameter and thickness is preferred in engineering.

3) The stiffness of soil will change the local stress state of pipe. It is good for reducing pipe stress to lay some loose soil at the bottom of the pipe.

4) The maximum axial stress of pipe near the junction of the two regions will increase with the increase of the buried depth. So shallow burying is benefit for protecting pipe.

\section{ACKNOWLEDGMENT}

This work was supported by the National Natural Science Foundation of China (No.51378172, 51308182), and Natural Science Foundation of Hebei Province (No.E2014209089, E2014208143).

\section{REFERENCES}

[1] B. A. Wols, P. van Thienen, "Modelling the effect of climate change induced soil settling on drinking water distribution pipes," Computers and Geotechnics, vol. 55, pp. 240-247, January 2014.

[2] B.A. Wols, K. van Daal, P. van Thienen, "Effects of Climate Change on Drinking Water Distribution Network Integrity: Predicting Pipe Failure Resulting from Differential Soil Settlement," Procedia Engineering, vol. 70, pp. 1726-1734, 2014.

[3] B.A. Wols, P. van Thienen, "Modelling the effect of climate change induced soil settling on jointed drinking water distribution pipes," Computers and Geotechnics, vol. 70, pp. 106-115, October 2015.

[4] X. P. Luo, S. L. Lu, J. F. Shi, X. Li, J. Y. Zheng, "Numerical simulation of strength failure of buried polyethylene pipe under foundation settlement," Engineering Failure Analysis, vol. 48, pp. 144-152, February 2015.

[5] Z. N. Yang, X. H. Bai, "Numerical analysis for influence of foundation collaps on buried pipelines," Science Technology and Engineering, vol. 14, pp.1671-1815, Novemeber 2014.

[6] H. Y. Gao, Q. M. Feng, "Response analysis for buried pipelines through settlement zone,” Earthquake Engineering and Engineering Vibration, vol. 17, pp. 68-75, March 1997.

[7] S. Limura, "Simplified mechanical model for evaluating stress in pipeline subject to settlement," Construction and Building Materials, vol. 18, pp. 469-479, July 2004.

[8] X. L. Wang, J. Shuai, J. Q. Zhang, "Mechanical response analysis of buried pipeline crossing mining subsidence area," Rock and Soil mechanics, vol. 32, pp. 3373-3378, 3386, November 2011. 